\title{
NEXOS DE INTERNACIONALIZAÇÃO E LÍNGUA INGLESA À LUZ DO PARADIGMA DO RACISMO EPISTÊMICO: O CASO DO FUTURE-SE
}

\author{
Nexus of Internationalization and English Language in the light of \\ Epistemic Racism: The Future-se case
}

Nicolas de Oliveira SANTOS Programa de pós-graduação em Letras: Linguagens e Representações Universidade Estadual de Santa Cruz nicolas.nicknos@gmail.com https://orcid.org/0000-0002-4522-5831

Gabriel NASCIMENTO Universidade Federal do Sul da Bahia gabriel.santos@csc.ufsb.edu.br https://orcid.org/0000-0002-7695-9264

Maria D'Ajuda ALOMBA RIBEIRO

Universidade Federal de Roraima profdajuda@gmail.com https://orcid.org/0000-0002-9183-9076

\begin{abstract}
RESUMO: Este artigo tem por finalidade analisar e discutir aspectos acerca dos nexos entre Internacionalização, Política Linguística, ensino de línguas, e o racismo epistêmico. Nesta perspectiva, analisaremos os parâmetros relativos às propostas do Future-se (BRASIL, 2020a), para refletir de que forma o impacto da medida ao ensino de línguas reforça o racismo epistêmico na Internacionalização do Ensino Superior, observando a língua em primeiro lugar, além de aspectos como migração e ideia de qualidade do ensino superior público brasileiro. $\mathrm{O}$ foco de análise aqui delineado visa observar a colonialidade por trás da língua, e como esta atua no domínio colonial, em sua naturalização homogeneizante (NASCIMENTO, 2020b), e como disto decorre certa idealização das línguas e das identidades por ela moldadas. Logo, partindo de nossa análise, discutimos a Internacionalização no Future-se em suas dimensões de racismo epistêmico, em nível linguístico, migratório, e da avaliação da qualidade educacio-
\end{abstract}

\footnotetext{
${ }^{1}$ Autor para correspondência.
}

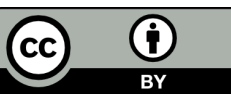


nal. Com isso, pretendemos provocar o debate epistêmico no próprio seio de campos como políticas linguísticas, ensino-aprendizagem de línguas, estudos de tradução, formação de professores, dentre outros. PALAVRAS-CHAVE: Internacionalização; Política Linguística; Racismo Epistêmico; Ensino de línguas.

ABSTRACT: This article aims at analysing and discussing aspects related to the nexus of Internationalization, Language Politics, Language teaching, and epistemic racism. In this perspective, we analyze the parameters assigned within the Future-se (BRASIL, 2020a) proposal, in order to reflect about the ways the impact of this measure to language teaching reinforces the epistemic racism on Internationalization of Higher Education, as it observes the language prior to aspect of migration and the idea of quality of Brazilian higher education. The focus of the analysis here designed seeks to observe the coloniality behind the language, and how this one acts within the colonial domain, in its homogenizing naturalization (NASCIMENTO, 2020b), and how this results in certain idealizations of the languages and the identities by formed by it. As a result, considering our analysis, we discuss the Internationalization on this proposal, in its dimensions of epistemic racism, on linguistic, migratory, and on evaluation of educational quality levels. With this, we aim at provoking the epistemic debate in the bosom of fields like linguistic politics, language teaching-learning, translation studies, teacher education, and others related. KEY-WORDS: Internationalization; Language Politics; Epistemic Racism; Language Teaching.

\section{INTRODUÇÃO}

Tangenciada por uma crescente demanda de globalização, ligada ao mercado global e a economia do conhecimento, a Internacionalização do Ensino Superior vinculase a princípios de aproximação, colaboração e solução de problemas advindos do contato entre instituições de diferentes localidades do mundo (SILVA; XAVIER, 2021). Em suas motivações e razões, tais processos se caracterizam numa diversidade de medidas, ações, políticas e sistemas educacionais, que são refletidas no cotidiano em formas de interação no contexto universitário.

Desta forma, em decorrência de uma necessidade imposta, relacionada tanto a comunicação global quanto ao encolhimento ou desaparecimento das fronteiras (MOLINARI; FRANCO; PASSONI, 2020), o papel da língua e da política linguística neste contexto é crucial para que se consolidem determinados objetivos ligados a este projeto, em que certos letramentos, usos, e formas linguísticas adquirem maior prestígio 
e favorecimento (GIMENEZ, 2020). Refletindo um pouco mais acerca da linguagem e suas manifestações neste contexto, evidencia-se o privilégio hegemonicamente outorgado à língua inglesa, requisitada ao acesso, participação e inclusão econômica, educacional e social (SHOHAMY, 2007), vinculada ao projeto de amoldamento ao sistema capitalista moderno, a globalização selvagem, e a manutenção do privilégio branco² (NASCIMENTO, 2019a), reproduzindo, desta maneira, uma visão de letramento ocasionalmente ligada ao progresso e ao desenvolvimento (MENEZES DE SOUZA, 2012).

Partindo deste escopo, podemos considerar a relação entre língua, lócus de enunciação e poder (NASCIMENTO, 2020b), demarcando como estes aspectos voltamse a manutenção das hegemonias, intimamente ligados a colonialidade, ao encobrimento do outro, ao epistemicídio, e a racialização. Logo, a desconsideração das linguagens das populações colonizadas e escravizadas, em suas maneiras variadas, é perpetuada através das relações linguísticas de poder (DAITCH; VERONELLI, 2021), de modo que a reprodução da lógica colonial capitalista é fundamentada na racialização e nas formas que toma esse fenômeno em um contexto de globalização e internacionalização.

Assim, neste artigo temos por objetivo analisar e discutir aspectos acerca dos nexos entre Internacionalização, Língua Inglesa e o racismo epistêmico. Nesta perspectiva, analisaremos os parâmetros relativos às propostas do Future-se (BRASIL, 2020a), para refletir de que forma o impacto da medida ao ensino de línguas reforça o racismo epistêmico na Internacionalização do Ensino Superior, observando a língua em primeiro lugar, além de aspectos como migração, ideia e qualidade do ensino superior público brasileiro.

O foco de análise aqui delineado visa observar a colonialidade por trás da língua, e como esta atua no domínio colonial, em sua naturalização homogeneizante (NASCIMENTO, 2020b), e como disto decorre certa idealização das línguas e das identidades por ela moldadas. Com isso, pretendemos provocar o debate epistêmico no próprio seio de campos como políticas linguísticas, ensino-aprendizagem de línguas, estudos de tradução, formação de professores etc.

Para tanto, primeiro vamos revisar criticamente o debate sobre internacionalização do ensino superior no Brasil para, em seguida, observar as interfaces entre ensino de línguas e internacionalização. Nesses dois aspectos vamos demarcar do ponto de vista empírico e teórico os aspectos ligados à definição do que entendemos por racismo epistêmico.

\footnotetext{
${ }^{2}$ Tomamos desta perspectiva a noção de branquitude, como o pacto narcísico entre os brancos que sustenta os privilégios raciais e seu status na modernidade, partindo da leitura de Nascimento (2020a apud Bento, 2002).
} 
Por fim, vamos analisar aspectos selecionados do programa para concluirmos de que de forma o programa reforça o racismo epistêmico na relação entre internacionalização do ensino superior e ensino de língua inglesa.

\section{INTERNACIONALIZAÇÃO DO ENSINO SUPERIOR}

Considerando as políticas institucionalizadas ligadas à promoção da aproximação de experiências internacionais junto ao ambiente universitário e acadêmico, as ações relativas à internacionalização do ensino superior passaram a ser expandidas de forma a acompanhar fluxos globalitários globais (SANTOS, 2000) que, através do neoliberalismo e da visão operatória da universidade, passam a atuar como um discurso que disciplina a criação de universidades supostamente globais, com trânsitos globais, como se as hierarquias regionais pudessem ser anuladas. Nesse sentido, ao falar da hegemonia de uma cidadania global, Menezes de Souza (2011) reposiciona práticas locais que resituam esses fluxos globalitários (isto é, que preconizam apenas um modelo de globalização, a do neoliberalismo). Como apontam Silva e Xavier (2021), os conceitos e abordagens desse modelo de internacionalização do ensino superior vão aparecer em diferentes formas, momentos e contextos. Assim, como elemento constituinte de processos globalitários (SANTOS, 2000), isso tem afetado também a construção e disseminação do conhecimento, impactando não somente o ensino superior, mas também a delimitação de supostas necessidades e habilidades que caracterizam o trabalho no mercado global (GIMENEZ, 2016).

Como processos que visam compor a esferas internacionais, interculturais e globais, integrando-as à vida, serviços e relações no ensino superior (KNIGHT, 2003 SILVA; XAVIER, 2021), esses aspectos da internacionalização afetam a educação e as formas políticas de seus contextos e atuação, muitas vezes impondo valores globais abstratos, eurocêntricos e racistas, ao moldar relações, interações e formas de compor e ocupar os espaços.

Dentre as diferentes formas que o conceito de Internacionalização do Ensino Superior assume, Silva e Xavier (2021) apontam para ideias de internacionalização abrangente, dentro do ambiente da instituição, do currículo, e educacional. Assim, num conceito abrangente, tais processos são vistos descaracterizadamente como relações que apenas envolvem a formação de compromissos relativos a ações que visem direcionar o conjunto dos costumes e hábitos fundamentais de determinada instituição, de maneira compreensiva e extensiva (HUDZIK, 2011 apud SILVA; XAVIER, 2021), sem que, com 
isso, se problematize a própria exclusão que surge da ideia de internacionalização na modernidade tardia ${ }^{3}$.

Relativo à compreensão das dimensões culturais e internacionais nos processos educacionais, as atividades curriculares, e as relações com grupos locais, o conceito de Internacionalização (WACHTER, 2003 apud SILVA; XAVIER, 2021), se volta ao ambiente da instituição, envolvendo o favorecimento de conteúdos que formem indivíduos com uma consciência global (que, por ser homogênea a partir do Norte global e de países centrais, é excludente e problemática), ao passo em que desfocam as medidas de mobilidade internacional e seus privilégios de acesso. São exemplos disso a universalização do mercado de capitais que, ao passo que impõe não protecionismo aos países pobres, geralmente os não-brancos, lhes impondo quase ou nenhuma soberania econômica, perpetua o protecionismo do norte global, em que países centrais como Estados Unidos e Alemanha aplicam taxas pesadas contra a importação de subsídios de fora do eixo Europa-Estados Unidos, por exemplo.

No mesmo sentido, a Internacionalização Educacional (DEWIT, 2011 apud SILVA; XAVIER, 2021) visa concretizar o desenvolvimento do ensino e das práticas e conhecimentos dos integrantes da comunidade acadêmica em geral, tendo como foco a ideia de qualidade e sustentabilidade destas relações.

Desta noção educacional deriva, pontualmente, o que caracteriza, ou não, os processos de internacionalização neste sentido, como uma "construção transformadora da cultura de uma instituição" (SILVA; XAVIER, 2021, p. 5587). Nesta perspectiva, a oferta de disciplinas em inglês, o foco na mobilidade acadêmica, o estabelecimento de parcerias internacionais consideradas como êxito, bem como a compreensão destes processos fora de suas realidades e necessidades contextuais, compõem um discernimento limitado e limitante deste fenômeno porque não necessariamente dialogam com qualidade e sustentabilidade das relações de fluxos globais e locais.

Todavia, não raro se veem ações relativas a esse contexto que se propõem, implícita e explicitamente, baseadas no poder de influência de regiões e países ricos guiados pelo mote da globalização, deixando de lado a ajuda mútua e igualdade nas relações de troca, a fim de angariar e reafirmar o controle do capital estrangeiro, subserviente a falta de investimento do meio público e a padrões excessivamente competitivos (SILVA; XAVIER, 2021). Por isso, temos falado de cooperação Sul-Sul, em que o sul global

\footnotetext{
${ }^{3}$ Compreendemos aqui Modernidade Tardia como o momento em que as sociedades modernas encontram-se "obrigadas a refletir sobre si e, ao mesmo tempo, desenvolvem a capacidade de refletir retrospectivamente sobre si (...).” (GIDDENS, 1997 apud LUVIZOTTO, 2010).
} 
possa se reconectar em torno de seus interesses, inclusive com relações entre o Brasil e países africanos.

A ideia da desconstrução de um imaginário de submissão e inferioridade intelectual, da hierarquia e dominação cultural como produtos dessa internacionalização, nos leva a questionar a própria motivação de tais processos, e como eles refletem aspectos ligados à comercialização da educação e a exploração estrangeira do potencial lucrativo local (FINARDI; GUIMARÃES; MENDES, 2020). Neste sentido, considerando as formas com que os processos globalitários afetam a produção e disseminação dos conhecimentos construídos na academia, o ensino superior sofre mudanças em suas atitudes administrativas e institucionais a fim de atender uma demanda puramente mercadológica, constituindo uma economia do conhecimento (GIMENEZ, 2016).

Parece então necessário questionar a conceituação deste processo como se ele fosse inevitavelmente benéfico, como se fosse proposto fora de contextos específicos e não atendesse demandas ligadas à meritocracia e ao mercado global, em perspectivas sociais e econômicas (GIMENEZ, 2020). Assim, concordamos com Silva e Xavier (2021) ao apontar que:

O risco encontrado aqui é que, sem muitos questionamentos críticos, diversos agentes da internacionalização acabam por executar atividades da educação internacional como commodity, difundidas por organismos multilaterais, tais como a Organização para a Cooperação e Desenvolvimento Econômico(OCDE) e o Banco Mundial, sob abandeira da internacionalização, sem reflexão sobre concretos ganhos para a qualidade educacional e a sua democratização (BRANDENBURG; DE WIT, 2011 apud SILVA; XAVIER, 2011, p. 5587)

Nesta perspectiva, e ainda seguindo os apontamentos de Silva e Xavier (2021) ao problematizarmos as abordagens sob as quais o ato de internacionalizar tem se pautado, percebemos que elas perpetuam padrões eurocêntricos e neocoloniais, agindo na manutenção das desigualdades de acesso à educação, ainda que políticas abrangentes e de grande importância na formação e qualificação dos estudantes tenham sido e estejam sendo desenvolvidas, pois costumam ser propostas a partir de lógicas de exclusão do local, as que neste texto, a partir de Grosfoguel (2016a; 2016b), chamaremos de racismo epistêmico. Bebendo na fonte do teórico Frantz Fanon, o autor assim define racismo epistêmico:

As pessoas classificadas acima da linha do humano são reconhecidas socialmente em sua humanidade como seres humanos e, portanto, 
como aquelas que acessam direitos (humanos, civis, de mulheres ou trabalhistas), recursos materiais, e reconhecimento social às suas subjetividades, identidades, epistemologias e espiritualidades. As pessoas abaixo da linha do humano são aquelas consideradas subhumanas ou não-humanas; o que significa que sua humanidade é questionada é, como tal, negada (Fanon, 19). No último caso, a extensão dos direitos, recursos materiais e reconhecimento de suas subjetividades, identidades, e espiritualidades e epistemologias são negadas (GROSFOGUEL, 2016b, p. 10, tradução nossa)

Especificamente, partindo da ideia de Santos e Menezes (2009) de que "epistemologia é toda noção, refletida ou não, sobre as condições do que conta como conhecimento válido" (p. 09), toda experiência social é parte da produção e reprodução do conhecimento, em aspectos culturais e políticos, em relações desiguais de poder. Assim, ainda dialogando com os autores, as diferenças epistemológicas encontram-se na base dos conflitos que permeiam as relações sociais, e, na modernidade, tais noções constituem as formas reguladoras da condição científica, adequando e situando os conhecimentos a serem validados, e que também favorece a consolidação do racismo epistêmico (NASCIMENTO, 2020a).

Tal reflexão, consequentemente, nos leva a ponderar as formas ideológicas que perpassam estes processos, como estes fixam as já estabelecidas relações Norte-Sul global, são cruciais para afirmar uma exclusão epistêmica que estamos chamando de racismo epistêmico. Esse racismo se organiza na internacionalização ao extinguir formas locais de existência que, anuladas, são obrigadas a reproduzir valores globais totalitários (que até aqui temos chamado de globalitários).

A ideia de zona do ser e zona do não-ser do teórico Frantz Fanon (2008) é fundamental para entendermos como a globalização homogeneíza o local, lhe tirando suas características originais. Fanon (2008) descreve a zona do não-ser pensando seu corpo negro colonizado, como um espaço de não humanização, assim não humanizado pelo próprio humanismo como discurso globalizante e desumanizador em nível global porque, ao passo que os brancos e europeus se humanizam durante a invasão colonial, eles passam a desumanizar ou não-humanizar cada corpo racializado em nível local. Ou seja, a internacionalização, longe de parecer fenômeno recente, é resultante de um processo de invasão colonial que resulta em tráfico negreiro. Em outras palavras, em nível universitário, ao esquecermos a majoração de um discurso globalitário único, esquecemos que a imposição de um valor global no ocidente tem suas marcas no próprio modelo de invasão colonial e escravização. 
No campo dos estudos linguísticos essa relação pode ser percebida na emergência de discussões de multilinguismo na modernidade tardia, como se essa característica fosse um privilégio do moderno, sendo que africanos no mundo pré-colonial já falavam diversas línguas, e ao mesmo tempo. O multilinguismo, a poliglossia e a própria expansão do ensino de inglês durante a ditadura são exemplos de como o neoliberalismo, em sua face racial, garante a cor e o corpo dos privilegiados pelo discurso da internacionalização: aqueles e aquelas brancos e brancas que têm dinheiro para pagar cursos de inglês privados que à época passam a expandir.

Outra relação que passa a ser difundida nos estudos linguísticos são os estudos de letramento que, após a guinada neoliberal no Brasil, vão ser ampliados após a pressão de organizações internacionais sobre alfabetização e desenvolvimento, em que a visão de linguagem, longe de ser crítica, é recriada na relação entre "eu", o norte global alfabetizado e letrado e o "outro", com maioria de analfabetos. Apesar das boas intenções, longe de combater esses valores, essa ampliação de estudos de letramento sem autocrítica de si acaba por reproduzir valores globais como a ideia de alfabetismo funcional, os rankings educacionais, mediados pelo Estado e pelo mercado. Embora o humanismo crítico de Paulo Freire em diversos momentos tenha nos dado valores de letramento popular, a visão de letramentos só passa a ser conhecida depois que o próprio Paulo Freire começa a ser conhecido no mundo anglófono, na hegemonia do inglês como língua monolíngue internacional, nos mostrando mais uma vez a marca do racismo epistêmico na internacionalização do ensino superior, que nos aponta o inglês como o único caminho possível global quando, na verdade, esse é apenas um caminho monolíngue.

\section{ENSINO DE LÍNGUAS E INTERNACIONALIZAÇÃO}

A ideia de língua global está ligada ao apagamento e erradicação do pensamento do outro, ao passo que "a língua é, como todo produto ou subproduto criado pela colonialidade, um espaço de atuação do epistemicídio." (NASCIMENTO, 2019a, p. 23). Fanon (2020) já apontava que o confronto entre as formas de vida local e do colonizador é frequente, ao passo que o uso de uma língua estrangeira implica num processo de deslocamento. Ainda segundo o autor, este é um confronto que decorre como resultado da privação e alienação dos povos colonizados de suas formas originais de se relacionar com o mundo e sua cultura.

Tratando-a como uma marca do pensar que herdamos da colonização, nesta perspectiva, a língua inglesa parece alinhar-se a maneiras hegemônicas de organizar as formas e vieses que o discurso do conhecimento pode tomar, o que consequentemente Revista X, v. 16, n. 6, p. 1528-1551, 2021. 
molda as identidades de seus usuários, desvalorizando formas genuínas e autônomas de comunicação em favor do mito de uma língua internacional e do falante nativo (JORDÃO, 2016). Tais manifestações da língua e suas formas de instrução parecem estar relacionadas a uma visão abstrata e descontextualizada de seus usos e de seus sujeitos, desconsiderando uma infinidade de práticas social e semioticamente situadas (MENEZES DE SOUZA, 2012). Deste modo, podemos concordar com a tese de Pennycook e Makoni (2007), de que as línguas são invenções, fabricações que remetem as relações de poder que as perpassam, sendo mitologicamente naturalizadas em nosso viver social, e que representam uma realidade material de normas, usos e letramentos.

Debatendo o fenômeno da língua inglesa como global e/ou internacional, o que parece defini-la neste paradigma é sua comunidade imaginada (ANDERSON, 1991 apud NASCIMENTO, 2019a), por meio de suas identidades idealizadas e do fetiche de perfeição e performance derivado da mentalidade moderna aliada ao helenismo greco-romano. Considerando a relação entre língua, lócus de enunciação e poder (NASCIMENTO, 2020b), nota-se, consequentemente, como estes aspectos voltam-se a manutenção das hegemonias, intimamente ligados a colonialidade, ao encobrimento do outro, ao epistemicídio (que aqui temos chamado de racismo epistêmico), e a racialização. Observando, então, o cenário de Internacionalização sob este prisma, infere-se que as relações linguísticas de poder promovem a desconsideração das linguagens e formas sociais de atribuir sentidos das populações historicamente colonizadas e escravizadas (DAITCH; VERONELLI, 2021), donde a racialização tem papel fundamental na reprodução da lógica colonial capitalista, aliada aos processos de globalização.

Pensando especificamente no status privilegiado que a língua inglesa carrega (MOLINARI; FRANCO; PASSONI, 2020; SHOHAMY, 2007), refletir acerca dos processos de internacionalização culmina pensar em como a língua se insere neste painel, debate que adquire grande importância junto aos estudos dos processos globalitários e seus impactos (GIMENEZ, 2016), para construção de um espaço de diferença que se quer excludente, daqueles que não falam a língua inglesa, ou não querem falar.

De certa forma, nossas atitudes, conhecimentos, e ideias são construções sociais moldadas pela constituição discursiva que temos contato e que utilizamos para nos relacionarmos com o mundo (CRISTÓVÃO; RADI, 2014). Ao pensarmos numa sociedade globalizada, donde sujeitos de diferentes contextos sócio culturais estão em constante contato, os repertórios que podem ser acessados para que haja comunicação e interação são inumeráveis, de forma verbal ou não verbal. Consequentemente, é crucial que se promovam políticas educacionais, bem como práticas sociais linguísticas, que 
afirmam e reforçam a identidade histórica dos falantes, sopesando negociações de sentido em contextos multilíngues (GARCIA; WEI, 2014; TAKAKI, 2019).

Nesta perspectiva, de acordo com Nascimento (2019b), ao pensarmos nos desafios relacionados aos processos de ampliação do acesso ao ensino superior vividos no Brasil nos últimos anos, tratamos neste artigo também do alcance que a língua Inglesa toma nestes contextos, nos quais comunidades negras e indígenas passam a ter maior contato com a língua estrangeira (ao português, já que, por vezes, o português pode ser uma língua estrangeira a essas comunidades). Considerando que as significações são negociadas nos usos linguísticos, uma possibilidade de revisar tal perspectiva é pensar, ou reinventar, a língua como meio de reforçar identidades racializadas, a fim de ressignificar opressões por meio da resistência, proporcionando que a aula de língua seja atmosfera susceptível a desconstrução do racismo estrutural (NASCIMENTO, 2019b).

Assim, ao pensarmos nos contextos de internacionalização, e no papel que a língua e as práticas linguísticas têm, em aspectos ideológicos e políticos, torna-se evidente a urgência de se repensar analisar, considerar, e propor políticas linguísticas, visando uma globalização que preze pela aceitação, inclusão, e participação ativa de todos os grupos sociais, a nível local, nacional e global (SHOHAMY, 2007). Assim sendo, as metodologias de ensino-aprendizagem, materiais didáticos, bem como a formação de professores, devem ser influenciadas por tal agenda relacionada à diversidade, justiça social e equidade étnico-racial.

Deste modo, este debate nos traz a esta encruzilhada, posicionando os sujeitos envolvidos nestes complexos processos, nisto incluso pesquisadoras e pesquisadores dos estudos da linguagem, professores e estudantes de línguas, e todos aqueles que direta e indiretamente sentem os impactos de medidas relativas à globalização e internacionalização da educação, apontando para a necessidade urgente de perspectivas, pontos de vista e teorias que deem conta de considerar efetivamente as problemáticas deste cenário de forma descentralizada, local e lúcida. Para tanto, voltemo-nos à linguística aplicada.

Os estudos relativos à Linguística Aplicada voltam-se as reflexões tecidas acerca do uso da linguagem em um mundo concreto, como apontam Menezes, Silva e Gomes (2009), em oposição a análises que tomam a língua de forma idealizada, estudando-a em relação a um contexto, e não como uma realidade imaginada, uma invenção assinada pelo próprio racismo epistêmico que, ao cria-la como invenção, apaga as práticas linguísticas de seus falantes desprivilegiados. Ainda de acordo com os autores "parece haver consenso de que o objeto de investigação da (LA) é a linguagem como prática social, seja no contexto de aprendizagem de língua materna ou outra língua, seja em qualquer 
outro contexto onde surjam questões relevantes sobre o uso da linguagem" (MENEZES; SILVA; GOMES, 2009, p. 01).

Desta forma, podemos pensar na evidência e importância da educação linguística, e como as perspectivas traçadas pela Linguística Aplicada podem salientar aspectos críticos acerca da linguagem em suas práticas sociais. Ainda, tais perspectivas envolvem orientações pragmáticas e transdisciplinares, o que permite questionar postulados ligados à idealização das línguas, sua suposta purificação e a escolha deste escopo como objeto científico (SILVA, 2015).

Desta forma, tendo como objeto de investigação a língua como prática social, as disposições apresentadas pela Linguística Aplicada e aqui discutidas nos fazem enxergar aspectos como questões ligadas aos aspectos monolíticos das evidências de pesquisa, perspectivas normativas e objetivamente fragmentadas da língua, formas com que as reflexões das usuárias e usuários das línguas são tratadas em modelos teóricos e metodológicos, bem como a priorização de desenvolvimento de estudos linguísticos por áreas do conhecimento em detrimento de problemáticas reais que concerne a linguagem (SILVA, 2015). Assim, como instrumento da construção do conhecimento e da vida social, a linguagem é atravessada, em seu acontecimento, por aspectos políticos, de modo que os estudos em Linguística Aplicada propiciam que se vislumbrem maneiras de entender complexidades sociais em que as formas comunicativas são nevralgicamente centradas (MOITA-LOPES, 2009).

Contudo, é importante ressaltar as relações entre esta área do conhecimento com ideais coloniais, porque, ao passo que teorias de ensino e aprendizagem de línguas foram e têm sido propostas por um viés mercantilista (MOITA-LOPES, 2009), contribuindo para a manutenção e produção das desigualdades sociais e para a hegemonia da língua inglesa (PENNYCOOK, 2001 apud SILVA; SANTOS; SOUZA, 2020), isso é resultante dos efeitos que o colonialismo faz a vida contemporânea herdar, isto é, a colonialidade.

Neste sentido, segundo Signorini em sua leitura de Rajagopalan (2003), enquanto construto usado para definir uma abordagem reflexiva e investigativa com relação à língua, as noções aqui apresentadas até então, longe de nos fazer ver apenas um dos lados da internacionalização, o mais sombrio, nos leva a interpelar o conceito de língua e identidade, apontando para temáticas como a globalização e sua relação com subjetivação, representação político-ideológica, política linguística, a identidade da pesquisa linguística e a participação social.

À vista disso, a fim de questionar a naturalidade dos fatos e gerar mudanças sociais significativas, a criticidade aliada aos estudos da linguagem e à análise da língua 
como prática social móvel e multiglóssica, nos leva a compreender que o saber está ligado ao sujeito, num contexto histórico-social, sendo então necessário reconecta-los, sendo a educação um meio possível (MENEZES DE SOUZA, 2012). Similarmente, ao relacionarmos estas perspectivas à ideia de sujeito e lócus de enunciação, notamos o delinear do espaço de onde se enuncia o discurso e a genealogia do poder, bem como a pessoa que o faz, em vias de marcar o não-marcado (MENEZES DE SOUZA, 2012; NASCIMENTO, 2020b).

Língua, lócus de enunciação e poder estão relacionados (NASCIMENTO, 2020b) e intimamente imbricados pela colonialidade, de modo que, se considerados como escopo de análise da globalização, permitem visualizar como as relações linguísticas de poder inferiorizam e hierarquizam as formas de usar a linguagem (DAITCH; VERONELLI, 2021), ao passo que a racialização tem papel fundamental na reprodução da lógica colonial capitalista que se entrelaça com esses dispositivos. Adicionalmente, analisando a lógica entre o conservadorismo, imperialismo, e neoliberalismo, podemos pensar no emaranhado complexo que forma e edifica a iniquidade educacional, e como estão relacionadas ao poder social e demandas culturais e linguísticas do capitalismo (WINDLE, 2019).

Assim, pensando criticamente acerca do fenômeno do Inglês como uma língua global, compreendemos que o impacto deste paradigma é amplo, influenciando, dentre outras esferas, a formação de professores e o ensino e aprendizagem de línguas, como aponta Leffa (2001), aliada a uma dimensão que concebe um monolinguismo global do inglês ao passo que poderia estar oferecendo a língua como complementar às línguas locais apenas.

Seguindo ainda os apontamentos do autor, o ensino que considera e se pauta no viver social dos estudantes é essencial para que se questione a representação da hegemonia cultural vinculada à língua, valorizando as experiências e vivências dos alunos como culturalmente relevantes. Ainda, essa perspectiva envolve a aceitação da diversidade presente na língua, através da promoção de variedades locais das línguas modernas, bem como o ensino voltado à produção, onde alunos falam, escrevem, ouvem, leem, e se comunicam de forma objetiva e efetiva na e pela língua (LEFFA, 2001).

Denota-se, portanto, potencial transformador no ensino de línguas, aliado a integrações interdisciplinares que envolvam reflexão de ordem social, cultural e ambiental, apoiados na concepção de linguagem como prática social. Nesta perspectiva, desenvolvem-se procedimentos metodológicos que visam abordar a linguagem como 
parte da vida real das pessoas, a fim de promover conscientização, reflexão crítica e ações sociais significativas (CRISTOVÃO; RADI, 2014), além do desenvolvimento linguístico.

Ainda, estratégias curriculares, focando em temáticas críticas, tornam a língua mais próxima dos aprendizes, de modo que é possível figurar o uso da língua como forma de ressignificar a opressão através da resistência (NASCIMENTO, 2019b). Tal potencial, articulado a fim de trazer à tona os debates acerca de raça e etnicidade, pode promover a manifestação crítica de identidades na e pela língua, proporcionando superar e repensar formas hegemônicas do uso de determinada língua através de sua aproximação ao cotidiano (NASCIMENTO, 2019b). Desse viés crítico, podemos figurar, por exemplo, um ensino de línguas tangenciado por uma perspectiva racial crítica (FERREIRA, 2015) que envolva a politização da presença de tal questão no ensino de línguas, utilizando-se do construto significante raça para se promover resistência no ensino de língua inglesa. Em linhas gerais, este posicionamento com relação à língua evidencia a dimensão política da prática docente, envolvendo a reafirmação ou oposição a discursos hegemônicos (LEFFA, 2001).

Para analisar um fenômeno recente que pode nos levar à análise da relação entre internacionalização do ensino superior, língua inglesa e racismo epistêmico, vamos analisar a seguir como o Programa Future-se constrói um projeto de internacionalização em que o racismo epistêmico é materializado.

\section{O CASO DO PROGRAMA FUTURE-SE}

O Programa Future-se foi lançado na gestão do ex-ministro da Educação Abraham Weintraub, como forma de provocar uma mudança estrutural no modelo de financiamento das universidades federais brasileiras. De acordo com o projeto de lei, o programa "busca o fortalecimento da autonomia administrativa, financeira e da gestão das universidades e institutos federais.", de acordo com o site do MEC e com o Projeto de Lei n. 3076/2020, mas, diferente do que diz a proposta, o programa visava acabar com o financiamento público de custeio e de capital das universidades públicas e impor em seu lugar um modelo de autogestão configurado a partir de um fundo soberano de pouco mais de 119 bilhões (sendo que esse seria um valor único para todas as universidades abandonarem seu atual modelo de financiamento estatal, e não um valor anual, como é atualmente) ${ }^{4}$.

\footnotetext{
4 Ver mais sobre o Future-se em <https://gtfuturese.paginas.ufsc.br/files/2019/08/Dossie\%CC\%82FUTURE-SE-ufba.pdf>. 
Sendo dividido em três eixos, Gestão, Governança e Empreendedorismo, Pesquisa e Inovação, e Internacionalização (BRASIL, 2020a), o programa volta-se às medidas do governo atual para as universidades federais (LEHER, 2021).

Especificamente no eixo 3, Internacionalização, de acordo com a Exposição de Motivos n. 00014/2020:

Os três pilares se relacionam de forma intrínseca e indissociável, de forma que, por exemplo, somente poderão ser celebradas parcerias internacionais efetivas e relevantes caso haja o desenvolvimento da potencialidade linguística dos atores da comunidade acadêmica. Por outro lado, a mobilidade internacional, que também depende de uma forte atuação da política linguística, será viabilizada por intermédio das parcerias internacionais em ensino, pesquisa e extensão. (BRASIL, 2020b).

Este projeto de lei propõe formas com que os discursos e seus saberes-poderes devem ser veiculados, em vias de padronizar as práticas educacionais relativas ao âmbito da internacionalização do ensino superior. Tendo como foco as trocas possíveis entre alunos e professores, a revalidação de títulos e certificação internacionais, a publicação e mobilidade para estudantes com alto desempenho acadêmico e atlético, a proposta apresenta uma visão simplista dos processos de internacionalização, guiada por demandas ligadas a meritocracia e a competitividade no mercado mundial, como aponta Gimenez (2020), caracterizando os objetivos estratégicos de consolidação de projetos políticos neoliberais (GERALDI; GERALDI, 2012).

Pontualmente, ao naturalizar desproporcionais relações internacionais, o documento não sopesa a valorização da cultura e valores nacionais, reafirmando uma subserviência colonial ao norte global (LEHER, 2021). Se pensarmos neste projeto enquanto parte de uma racionalidade política que reproduz uma lógica colonial, notamos, então, seus interesses e finalidades, e, ao se referir ao desenvolvimento da potencialidade linguística, e à dependência de forte atuação da política linguística, o cerne do documento reproduz o racismo epistêmico ao escolher como sujeito oculto o que entende por global, isto é, os países centrais, sobretudo os Estados Unidos, a quem o projeto e o governo é vinculado e parecem ser subservientes.

O Future-se, entre o seus valores de internacionalização, propõe:

I - a realização de cursos de idiomas para os docentes, por meio de parcerias com instituições privadas, para promover a publicação em periódicos no exterior (BRASIL, 2020b) 
Pela primeira vez, em mais de 80 anos, os interesses explícitos do mercado passam à frente da construção de um ensino público de idiomas. Para além disso, essa proposta entende os docentes como monolíngues ou incapazes, sendo que, para além de um ensino para estudantes, e do foco ter passado do ensino público para instituições privadas, os professores são vistos como alvo da política por supostamente não terem competência linguística.

É importante salientar que, diferente de instituições públicas, os centros privados de idioma não têm sua competência aferida por nenhum órgão oficial ou corpo de especialistas. Esses centros, por outro lado, são repletos de corpos brancos vistos como aptos ao aprendizado linguístico, seja por seu privilégio de cor ligado aos capitais econômicos e culturais, seja pela própria visão de inglês padrão branco que é ensinado nesse espaço. Ou seja, o que faz com que o programa tenha predileção pela rede privada ao invés da pública não é a qualidade, mas uma visão de língua inglesa globalitária.

Além disso, o programa propõe:

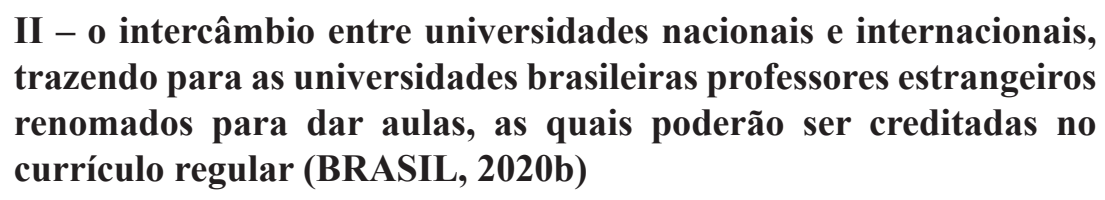

Esse tópico não é novidade nas políticas de internacionalização no país. Desde a década de 1930, pelo menos, há acadêmicos do exterior que atuam em instituições brasileiras. Porém, desde essa época, a preferência nunca foi pela cooperação sul-sul, ou entre países latino-americanos, ou com países africanos. Ou seja, ainda que não marcado, o sujeito oculto desse intercâmbio são universidades mercadológicas do norte global que queremos imitar e que não têm o mesmo objetivo de popularização, democratização e interiorização que nossas universidades federais, as novas e as velhas, criadas ou expandidas a partir do Programa do Governo Federal de Apoio a Planos de Reestruturação e Expansão das Universidades Federais Brasileiras (Reuni) ${ }^{5}$. Ou seja, ao passo que poderíamos estar nos relacionando com universidades que enfrentam dilemas parecidos de formação para o desenvolvimento regional no sul global, apenas queremos nos relacionar com universidades globais cujos modelos de seleção não recrutam nem metade dos estudantes de nossas instituições. A Universidade de Harvard, por exemplo, uma das mais populosas do mundo, tem, no máximo, 23 mil estudantes enquanto uma das nossas universidades públicas mais populosas, a Universidade de São Paulo, cujo

\footnotetext{
${ }^{5}$ Ver mais sobre o programa em $<$ http://www.reuni.ufscar.br/o-que-e-reuni.html $>$. 
modelo há muito tempo vem assimilando valores de universidades globais, tem quase 95.000 estudantes. O racismo epistêmico nesse caso lembra aquilo que Rosa e Flores (2017) chamaram de branco falante-ouvinte ideal, isto é, um sujeito branco que, embora não-marcado, padroniza nossas escolhas linguísticas. Nesse caso, é a escolha por universidades globais do norte que, embora não marcadas, está no plano.

Assim, a subalternização das comunidades que não acessam os repertórios comunicativos estipulados junto a este projeto político de internacionalização articula o racismo epistêmico e linguístico, portanto, ao desprezar a diversidade de formas sociais de dar sentido ao mundo, como se não fosse possível ensinar inglês sem se reproduzir essa visão globalitária. Tais relações de poder se materializam de diversas maneiras no curso da história capitalista, podendo ser apontados fatos como, por exemplo, a noção de letramento como habilidade homogênea universal (SOUZA, 2011), o monolinguismo (DAITCHI; VERONELLI, 2021) e a cultura do padrão monoglota (SILVA; LOPES, 2019), a imposição da norma culta, e, ainda, a noção de Inglês como língua global (NASCIMENTO, 2019a), de modo que esta política linguística corrobora para a reprodução deste paradigma histórico.

Além disso, diz o programa que vai assegurar:

\section{I - o fluxo contínuo de intercâmbio de professores, fomentando a pesquisa e uma melhor colocação nos índices e rankings internacionais (BRASIL, 2020b).}

Mais uma vez aqui a visão de ranking internacional responde a uma premissa interna de nossa incompetência. Não podemos, nós mesmos, criarmos modelos de avaliação, dentre os quais alguns existentes, como o Sistema Nacional de Avaliação de Ensino Superior (SINAES), Lei 10.861/2004, passarmos a ficar reféns de rankings que, muitas vezes, não contam com nossos especialistas como observadores. $\mathrm{O}$ pano de fundo dessa análise pretende disseminar a ideia de incompetência em vários níveis.

Por isso, para elencar como interpretamos esses dados nos níveis de racismo epistêmico, elencamos as dimensões a seguir a partir de uma série de sujeitos ocultos epistêmicos, que revelam a preferência do programa: 
Quadro 1: Internacionalização no Future-se em suas dimensões de racismo epistêmico.

\begin{tabular}{|c|c|}
\hline DIMENSÃO LINGUÍSTICA & $\begin{array}{c}\text { O inglês é o sujeito oculto dos cursos } \\
\text { de idiomas pretendidos pelo programa } \\
\text { e os docentes como alvo, sendo aqueles } \\
\text { incompetentes linguisticamente em inglês }\end{array}$ \\
\hline DIMENSÃO MIGRATÓRIA & $\begin{array}{c}\text { O Norte global é o sujeito oculto da dimensão } \\
\text { migratória e de mobilidade de pesquisadores. }\end{array}$ \\
\hline DIMENSÃO DE AVALIAÇÃO DA & $\begin{array}{c}\text { O pesquisador brasileiro e a universidade são } \\
\text { vistos como incapazes de avaliar e produzir } \\
\text { ranqueamentos, embora o Brasil já tenha } \\
\text { sistemas públicos de avaliação. }\end{array}$ \\
\hline
\end{tabular}

Fonte: autoria própria com bases nos resultados apresentados neste trabalho.

A relação do inglês com essas dimensões é a visão de monolinguismo que esse racismo epistêmico apresenta como do pesquisador brasileiro, sendo este incapaz de, antes de tudo, falar a língua inglesa, uma vez que essa é a primeira proposta trazida pelo programa. Ou seja, há também um jogo de preferências onde à visão de língua, longe de parecer implícita, é o carro chefe da ideia de incapacidade ou incompetência.

Além disso, ao deixar de prever a incorporação de línguas minoritárias, por não integrarem a lógica capitalista de trabalho (OLIVEIRA, 2009), a proposta do programa atrela-se a uma visão de letramento restrita e elitista, excludente em vista de uma variedade semiótica real das formas comunicativas (MENEZES DE SOUZA, 2012), bem como se alinha aos projetos ligados a manutenção do privilégio social, cultural e epistemológico dos povos ocidentais (NASCIMENTO, 2019a). Ainda, ao estimular uma economia do conhecimento, notamos que a proposta calça, implicitamente, seus objetivos baseada prioritariamente na influência que regiões e países ricos, ligados ao norte global, exercem em favor da globalização, desconsiderando a possibilidade de apoio mútuo e relações equânimes de troca, reafirmando o poder do capital estrangeiro e padrões competitivos e meritocráticos (SILVA; XAVIER, 2021). Dessa maneira, ela se caracteriza como ferramenta do racismo epistêmico ao reproduzir politicamente uma lógica de apagamento e subtração do outro, favorecendo determinados sujeitos e formas comunicativas, formato por qual a colonialidade cria e recria-se como instrumentos de si (DUSSEL, 1993, apud NASCIMENTO, 2019). 
Dentre os impactos pedagógicos, ainda que não materializado até aqui, este documento norteador pode influenciar nas práticas escolares e no ensino de línguas estrangeiras nos contextos do ensino superior, promovendo a domesticação dos agentes educacionais (GERALDI; GERALDI, 2012). Não somente tratando da formação de professores, produção de materiais didáticos e metodologias, elementos consideráveis e cruciais a manutenção de determinadas formas hegemônicas, mas também com relação às escolhas linguísticas que podem ser realizadas nestes meios, apontando, por exemplo, para a historicamente perpetuada ultra valorização da língua inglesa, para a imposição sutil ou explícita de determinadas identidades, em sua maioria branco-eurocentradas, para a homogeneização das formas de aprender e ensinar, para a dominação ideológica, materializando e legitimando a produção e circulação de saberes e suas relações de poder.

\section{CONSIDERAÇÕES FINAIS}

Em suma, as proposições delineadas neste trabalho, e na discussão que o compõem, objetivaram-se a analisar e discutir as relações entre Políticas Linguísticas e Educacionais, Internacionalização e Língua Inglesa, envolvendo questões de ensino/aprendizagem e o papel da língua nas relações sociais sob o escopo delineado pela Linguística Aplicada. Deste modo, observando o rumo tomado pelo debate, algumas considerações podem ser tecidas.

Considerando as formas com que os processos de internacionalização do ensino superior se organizam, esse contexto propõe ainda muitos desafios a serem enfrentados. Partindo do pressuposto de que a formação de relações de ordem social e cultural e o poder de agência frente a situações de opressão envolvem a linguagem e seus usos (SILVA; XAVIER, 2021), denota-se o papel da língua, da política linguística, e do ensino e aprendizagem de línguas nesse contexto. Logo, ao refletirmos acerca das formas com que a linguagem integra esse cenário, somos levados a tratar das relações de poder que a atravessam por um ponto de vista indagador, observando as iniquidades relacionadas ao acesso e uso de determinados repertórios comunicativos (GIMENEZ, 2020). Desta forma, evidencia-se a necessidade de que se considerem conjunturas e circunstâncias educacionais que promovam a superação das iniquidades advindas do colonialismo (NASCIMENTO, 2019).

O enfoque dado a estes processos nos levam, então, a seus impactos ao ensino e aprendizagem de língua inglesa, e em como esta é conceituada, organizada, e veiculada, afirmando então a necessidade urgente de perspectivas, pontos de vista e teorias que deem conta de considerar de forma adequada as problemáticas apresentadas. Ou seja, a 
internacionalização, como compreendida pelo programa, ignora as identidades locais e promove a ideia de subserviência a um global que é racista epistêmico, em que o local, para ser aceito, terá que desidentificar suas universidades e produzir apenas um espaço operatório para o mercado.

Por fim, é importante ressaltar que não nos opomos aos processos relativos à Internacionalização do Ensino superior, sendo também parte deste complexo paradigma de interesses políticos, econômicos, e educacionais de ordem global; todavia vemos como parte nevrálgica de sua consolidação o constante questionamento acerca de seus motivos e motivações, de suas manifestações e resultados. Assim, enxergamos que o debate alocado por esta análise permite avaliar os nexos de Internacionalização e Ensino de Língua Inglesa, questionando como estes criam dispositivos como a colonialidade da linguagem (VERONELLI, 2016), que cria ampla dependência entre o mundo colonial e a produção da linguagem a partir dele, o racismo linguístico (NASCIMENTO, 2019c), como a dependência entre o racismo e a racialização de corpos negros no mundo colonial, e o epistêmico, sendo este como aquele que une o racismo linguistíco e a colonialidade da linguagem, na forma como a internacionalização descaracteriza e apaga a diferença, promovendo uma ambiência homogênea a partir de uma única forma de enxergar o global.

Restam, afinal, mais questões a serem pensadas, como: "Por que uma universidade deve ser internacionalizada?" e "Quem acessa e se beneficia destes processos?". Possivelmente, conjecturar acerca destes questionamentos nos levará a debates que inquirem a naturalidade destes processos, propondo então que se marque o não-marcado, questionando as identidades ligadas ao discurso ocidental e a branquitude, e sua manifestações nas políticas educacionais linguísticas, nas ações institucionais, nas pedagogias, na formação de professores, e na própria percepção acerca da Internacionalização.

\section{REFERÊNCIAS}

ARAÚJO, A. P. QECR e o ensino de Português Língua Estrangeira: autonomia e alteridade. In: RIBEIRO, M. D. A. Português como língua estrangeira na UESC: questões identitárias. Ilhéus: Editus, 2012. p. 209-223.

BRASIL, Secretaria-Geral. Ministério da Educação. Ministério da Ciência, Tecnologia, Inovações e Comunicações. Ministério da Economia. Exposição de Motivos n. 00014/2020, Brasília, DF: Secretaria-Geral, 3 abr. 2020a. Disponível em: http://www.planalto.gov.br/ ccivil_03/Projetos/ExpMotiv/MECON/2020/14-ME.htm Acesso em: 28 jul. 2021. 
BRASIL. Secretaria-Geral. Projeto de Lei n. 3076/2020, de 2 de junho de 2020. Institui o Programa Universidades e Institutos Empreendedores e Inovadores - Future-se. Brasília, DF: Secretaria-Geral, 2 jun. 2020b. Disponível em: http://www.planalto.gov.br/ CCIVIL_03/Projetos/PL/2020/msg302-maio2020.htm . Acesso em: 28 jul. 2021.

CRISTOVÃO, V. L. L.; RADI, A. J.. Educação Ambiental e Ensino de Língua Inglesa: contribuições para Educação Básica. In: EL KADRI, M.; PASSONI, T. P.; GAMERO, R. (org.). Tendências contemporâneas no ensino de língua inglesa: propostas didáticas para a Educação Básica. Campinas, Pontes Editora, 2014.

DAITCH, S.; VERONELLI, G. Sobre a Colonialidade da Linguagem. Revista X, v. 16, n. 1, 2021, p. 80-100.

FANON, F. Pele Negra Mascaras Brancas. Salvador: EdUFBA, 2008.

FANON, F. Pele Negra, Máscaras Brancas. Traduzido por Sebastião Nascimento e colaboração de Raquel Camargo. São Paulo: Ubu Editora, 2020.

FERREIRA, A. J. Letramento Racial Crítico Através de Narrativas Autobiográficas: com atividades reflexivas. 1. ed. Ponta Grossa: Estúdio Texto, 2015. v. 1. 208p.

FINARDI, K. R.; GUIMARÃES, F. F.; MENDES, A. R. Reflecting on Brazilian higher education (critical) internationalization. Revista Internacional de Educação Superior, v. 6, p. 01-23, 7 nov. 2019. Disponível em: https://periodicos.sbu.unicamp.br/ojs/index. php/riesup/article/view/8655312/21576. Acesso em: 28 jul. 2021.

FOUCAULT, M. Sobre a história da sexualidade. In: FOUCAULT, M. Microfísica do poder. Organização e tradução: Roberto Machado. Rio de Janeiro: Edições Graal, 1979.

GARCIA, O., WEI, L. Translanguaging: language, bilingualism and education. London: Palgrave, 2014.

GERALDI, C. M. G.; GERALDI, J. W. A domesticação dos agentes educativos: há alguma luz no fim do túnel. Revista Inter Ação, Goiânia, v. 37, n. 1, p. 37-50, 2012. Disponível em: https://doi.org/10.5216/ia.v37i1.18867. Acesso em: 31 jul. 2021.

GIMENEZ, T. English as a global language and the internationalization of universities. In: BASURTO-SANTOS, N.; CÁRDENAS, M. L. (ed.). Investigaciones sin fronteras: new and enduring issues in foreign language education. Research without borders: temas nuevos y perdurables en lenguas extrangeras. México: Universidad Veracruzana, 2016. 
GIMENEZ, T. Language Issues in the Internationalization of Higher Education in Brazil. In: Calvo, L. C. S. (org.) et al. Language Policies and Internationalization of Higher Education Institutions in Brazil: contributions from applied linguists. Campinas, SP: Pontes Editores, 2020. p. 7-10.

GROSFOGUEL, R. A estrutura do conhecimento nas universidades ocidentalizadas: racismo/sexismo epistêmico e os quatro genocídios/epistemicídios do longo século XVI. Sociedade e Estado. v. 31, n. 1, 2016.

GROSFOGUEL, R. What is Racism? Journal of World-Systems Research, v. 22, n. 1, 9-15, 2016.

GROSSFOGUEL, R. Descolonizando los universalismos occidentales: el pluriversalismo transmoderno decolonial desde Aimé Césaire hasta los zapatistas. In: CASTRO-GÓMEZ, S.; GROSSFOGUEL, R. (ed.) El giro decolonial: reflexiones para una diversidad epistémica más allá del capitalismo global. Bogotá: Siglo del Hombre Editores; Universidad Central, Instituto de Estudios Sociales Contemporáneos y Pontificia Universidad Javeriana, Instituto Pensar, 2007.

JORDÃO, C. M. Decolonizing identities: English for internationalization in a Brazilian university. Interfaces Brasil/Canadá, v. 16, p. 191-209, 2016. Disponível em: https:// periodicos.ufpel.edu.br/ojs2/index.php/interfaces/article/view/7683. Acesso em: 30 maio 2021.

LEFFA, V. J. Aspectos políticos da formação do professor de línguas estrangeiras. In: LEFFA, V. J. (org.). O professor de língua estrangeira; construindo a profissão. Pelotas, v. 1, p. 333-355. 2001. Disponível em: http://www.leffa.pro.br/textos/trabalhos/formacao. pdf. Acesso em: 30 maio 2021.

LEHER, R. Universidade pública federal brasileira: future-se e "guerra cultural" como expressões da autocracia burguesa. Educação \& Sociedade [online]. 2021, v. 42. Disponível em: https://doi.org/10.1590/ES.241425. ISSN 1678-4626. https://doi. org/10.1590/ES.241425. Acesso em: 25 maio 2021.

LUVIZOTTO, C.K. As tradições gaúchas e sua racionalização na modernidade tardia. São Paulo: Editora UNESP: Cultura Acadêmica, 2010. 140 p. Disponível em: http://books.scielo.org/id/cq8kr/pdf/luvizotto-9788579830884-05.pdf. Acesso em: 06 set. 2021. 
MENEZES DE SOUZA, L. M. T. Engaging the global by re-situating the local: (Dis) locating the literate global subject and his view from nowhere. In: ANDREOTTI, V. O.; SOUZA, L. M. T. M. (org.) Postcolonial Perspectives on Global Citizenship Education. Londres: Routledge, 2011, v. 1, p. 1-246.

MENEZES, V.; SILVA, M. M.; GOMES, I.F. Sessenta anos de Linguística Aplicada: de onde viemos e para onde vamos. In: PEREIRA, R. C.; ROCA, P. Linguística Aplicada: um caminho com diferentes acessos. São Paulo: Contexto, 2009.

MOITA-LOPES, L. P. Da aplicação de linguística à linguística aplicada indisciplinar. In: ROCA, P.; PEREIRA, R. C. (org.). Linguística aplicada: um caminho com diferentes acessos. São Paulo: Contexto, 2009. p. 11-24.

MOLINARI, A. C.; FRANCO, S. A. P.; PASSONI, T. P. Formação de professores de línguas em contexto de internacionalização. Revista NUPEM, Campo Mourão, v. 12, n. 26, p. 62-80, maio/ago. 2020. Disponível em: http://revistanupem.unespar.edu.br/index. php/nupem/article/view/703/441. Acesso em: 31 maio 2021.

NASCIMENTO, G. Do limão faço uma limonada: estratégias de resistência de professores negros de língua inglesa. 2020. 225 f. Tese (Doutorado) /FFLCH-USP, Depto de Letras Modernas. São Paulo, 2020. Disponível em: https://doi.org/10.11606/T.8.2020. tde-23092020-130036. Acesso em: 06 Set. 2021.

NASCIMENTO, G. Ethnicity and race in english language activities at a university in Bahia. Cadernos de Pesquisa, São Paulo, v. 49, n. 173, p. 208-224, set. 2019. Disponível em https://doi.org/10.1590/198053146287. Acesso em: 31 maio 2021.

NASCIMENTO, G. O negro-tema na Linguística: rumo a uma descolonização do racialismo e do culturalismo racialista nos estudos da linguagem. Polifonia, Cuiabá-MT, v.27, n.46, p. 01 a 235, abr./jun. 2020. Disponível em: https://periodicoscientificos.ufmt. br/ojs/index.php/polifonia/article/view/9560. Acesso em: 31 maio 2021.

NASCIMENTO, G. Racismo Linguístico: os subterrâneos da linguagem e do racismo. Belo Horizonte: Letramento, 2019.

OLIVEIRA, G. M. Plurilinguismo no Brasil: repressão e resistência linguística. Synergies Brésil, n. 7, 2009, p. 19-26.

PENNYCOOK, A.; MAKONI, S. Desinventing and Reconstituting Languages. In: PENNYCOOK, A.; MAKONI, S. Desinventing and Reconstituting Languages, p. 1-41. Clevendon: Multilingual Matters, 2007. 
ROSA, J.; FLORES, N. Unsettling race and language: Toward a raciolinguistic perspective. Language in Society, v. 46, n. 5, p. 621-647, 2017.

SANTOS, B.S.; MENESES, M. P. Introdução. In: SANTOS, SANTOS, B.S.; MENESES, M. P. (org.) Epistemologias do Sul. São Paulo; Editora Cortez. 2010.

SANTOS, M. Por uma outra globalização: do pensamento único à consciência universal. Rio de Janeiro: Record, 2000.

SHOHAMY, E. Reinterpreting globalization in multilingual contexts. International Multilingual Research Journal, v. 1, n. 2, p. 127-133, 2007. Disponível em: https:// www.tandfonline.com/doi/full/10.1080/19313150701495421. Acesso em: 31 maio 2021.

SIGNORINI, I. Por uma linguística crítica: linguagem, identidade e a questão ética. D.E.L.T.A, v. 19, n. 2, p. 381-387, 2003. Disponível em: Acesso em: 06 Set. 2021

SILVA, D. N. A propósito de Linguística Aplicada: 30 anos depois: quatro truísmos correntes e quatro desafios. D.E.L.T.A., vol. 31, p. 349-376, 2015. http://dx.doi. org/10.1590/0102-445007158226872892

SILVA, D. N.; LOPES, A. C. "Yo hablo un perfeito portuñol": Indexicalidade, ideologia linguística e desafios da fronteira a políticas linguísticas uniformizadoras. Revista da ABRALIN, v. 17, n. 2, 27 jun. 2019.

SILVA, K. A.; SANTOS, K. H. C.; SOUSA, J. M. M. O Ensino de Português do Brasil: uma herança, um acolhimento. In: SILVA, K. A.; SOUZA, A. (orgs.). O ensino de PLAc e a (re)construção identitária de imigrantes em situação de refúgio. JNP Books Education p.145. 2019.

SILVA, K. A.; XAVIER, R. P. Um panorama da Internacionalização da Educação superior na área do ensino de línguas adicionais e da pesquisa no Brasil. In: SILVA, K. A.; XAVIER, R. P. (org.) Fórum linguístico/ Programa de Pós-graduação em Linguística. Universidade Federal de Santa Catarina. Florianópolis: Universidade Federal de Santa Catarina, Pós-graduação em Linguística, v. 18, n. 1, 2021.

TAKAKI, N. H Towards Translanguaging with Students at Public School: multimodal and transcultural aspects in meaning making. Calidoscópio, São Leopoldo, v.17, n. 1, p. 163 183, jan./abril 2019. Disponível em: http://revistas.unisinos.br/index.php/calidoscopio/ article/view/cld.2019.171.09. Acesso em: 31 maio 2021.

VERONELLI, G. A coalitional approach to theorizing decolonial communication. Hypatia, v. 31, n. 2, p. 404-420, 2016. 
WINDLE, J. Neoliberalism, imperialism and conservatism: tangled logics of educational inequality in the global South, Discourse: Studies in the Cultural Politics of Education, 2019. Disponível em https://10.1080/01596306.2019.1569878. Acesso em 31 maio 2021.

Recebido em: 31 jul. 2021. Aceito em: 18 set. 2021.6 